Abstract OP0247 - Table 1 Preformance of the referral strategies against the rheumatologist clinical diagnosis ( $\mathrm{N}=3,877$; pre-test probability: $1.6 \%$ - weighted national SpA prevalance)

\begin{tabular}{lcccc} 
& $\begin{array}{c}\text { Sensitivity } \\
(\%)\end{array}$ & $\begin{array}{c}\text { Specificity } \\
(\%)\end{array}$ & $\begin{array}{c}\text { PPV } \\
(\%)\end{array}$ & $\begin{array}{c}\text { 1-NPV } \\
(\%)\end{array}$ \\
\hline ASAS & 85.4 & 38.8 & 2.2 & 0.6 \\
EpiReumaPt & 72.1 & 67.6 & 3.5 & 0.7 \\
CafaSpA one & 56.3 & 69.7 & 2.9 & 1.0 \\
Brandt I & 49.2 & 79.3 & 3.7 & 1.0 \\
Braun IBP & 47.5 & 78.7 & 3.5 & 1.1 \\
MASTER & 36.7 & 87.7 & 4.6 & 1.2 \\
Brandt II & 27.7 & 92.4 & 5.6 & 1.3 \\
Hermann & 22.4 & 93.2 & 5.1 & 1.3 \\
CafaSpA two & 15.2 & 95.2 & 4.9 & 1.4 \\
Braun 2 step & 15.1 & 95.7 & 5.3 & 1.4 \\
Brandt III & 7.9 & 98.4 & 7.6 & 1.5 \\
\hline ASAS I I1/5+1 IBPS
\end{tabular}

ASAS ( $\geq 1 / 5+$ ): IBP (ASAS definition), good response to NSAIDs, family history of SpA, peripheral manifestations (arthritis, enthesitis and/or dactylitis), extra-articular manifestations (uveitis, psoriasis and/or IBD); EpiReumaPt ( $\geq 1 / 5+)$ : previous SpA/PSA diagnosis, IBP ( $23 / 8$ features), CBP ( 23 months) starting $<45$ years and $\geq 1 / 6 \mathrm{SpA}$ features, dactylitis, enthesitis; CafaSpA one ( $\geq 1 / 3+$ ): IBP (ASAS definition), good response to NSAIDs, family
history of SpA; CafaSpA two ( $\geq 2 / 3+$ ): see CafaSpA one; Brandt I ( $\geq 1 / 1+1):$ IBP (morning stiffness $>30 \mathrm{~min}$, pain at

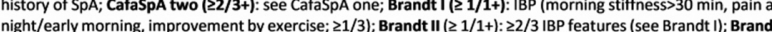
night/early morning, improvement by exercise; $21 / 3)$; Brandt II $(\geq 1 / 1+1)$ : $\geq 2 / 3$ IBP features (see Brandt I); Brandt night, alternating buttock pain, improvement by movement, not rest; MASTER $(\geq 2 / 3+$ ): IBP (morning night, alternating buttock pain, improvement by movement, not rest; MASTER $(\geq 2 / 3+)$ : IBP (morning
stiffness $>30$ min, improvement exercise, not rest, awakening in the night because of BP), good response to stiffness $>30$ min, improvement exercise, not rest, awakening in the night because of BP), good response to
NSAIDs, family history of AS; Hermann ( $(21 / 1)$ : IBP (Calin's criteria): Braun 2 step (2 2/3): psoriasis, alternating NSAIDs, family history of AS; Hermann ( $21 / 1)$ : IBP (Calin's criteria): Braun 2 step ( $22 / 3)$ : psoriasis, alternating CRP/ESR excluded from ASAS.

Conclusions: For the first time, a wide range of SpA RS were tested head-tohead in a population-based setting where the ASAS and EpiReumaPt RS were shown to be the most sensitive. Our data suggest that these strategies can be effectively used as screening tools for SpA especially when laboratory and imaging data are not available.

Disclosure of Interest: None declared

DOI: 10.1136/annrheumdis-2018-eular.2761

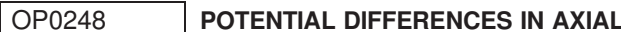 SPONDYLOARTHRITIS DISEASE ACTIVITY CATEGORIZATION USING DIFFERENT MINIMUM VALUES FOR HIGH-SENSITIVITY CRP IN ANKYLOSING SPONDYLITIS DISEASE ACTIVITY SCORE CALCULATION AND DIFFERENT DEFINITIONS OF DISEASE FLARE}

R. Landewé $^{1}$, J. Sieper ${ }^{2}$, U. Kiltz ${ }^{3}$, X. Wang ${ }^{4}$, M. Li ${ }^{4}$, J. Anderson ${ }^{4} .{ }^{1}$ University of Amsterdam, Amsterdam, Netherlands; ${ }^{2}$ Charité Universitätsmedizin Berlin, Berlin; ${ }^{3}$ Rheumazentrum Ruhrgebiet, Herne, Germany; ${ }^{4}$ AbbVie Inc., North Chicago, USA

Background: It has been recommended that the lower limit of high-sensitivity CRP (hsCRP) be restricted to 2 in the Ankylosing Spondylitis Disease Activity Score (ASDAS) calculation. Also, a definition of flare of ASDAS increase $\geq 0.9$ was recently proposed.

Objectives: Using non-radiographic axial $\mathrm{SpA}(\mathrm{nr}-\mathrm{axSpA})$ trial data, this analysis evaluated potential differences in patient (pt) categorization using different minimum values for hsCRP in the ASDAS calculation and different definitions of disease flare.

Methods: ABILITY-3 (NCT01808118) assessed the impact of continuation versus withdrawal of adalimumab (ADA) in nr-axSpA pts who achieved sustained remission with open-label ADA. All pts received open-label ADA $40 \mathrm{mg}$ every other wk during a 28-wk lead-in period. Pts who achieved remission, defined as ASDAS inactive disease (ID, ASDAS <1.3) at wks 16, 20, 24, and 28 were randomised to 40-wk, double-blind ADA (continuation) or PBO (withdrawal). ASDAS was calculated with the full range of hsCRP (protocol-defined) and limiting hsCRP to the lowest possible value of $2 \mathrm{mg} / \mathrm{L}$ (rederived). Flare was calculated as 2 consecutive study visits with ASDAS >2.1 (protocol definition) or with ASDAS increase $\geq 0.9$ (modified definition). Data are reported as observed (open label) and by nonresponder imputation (double blind).

Results: 673 pts were enrolled. At open-label baseline, mean ASDAS using the protocol-defined ASDAS calculation was 3.6 vs 3.7 when rederived. At wk 28, 295 (43.8\%) pts achieved protocol-defined ASDAS ID vs $272(40.4 \%)$ pts using the rederived ASDAS; mean ASDAS at double-blind baseline was 0.7 vs 0.9 , respectively. At wk 68, significantly more pts treated with ADA vs PBO had no flare per protocol definition $(69.7 \%$ vs $47.1 \%$; $p<0.001$; table 1$)$. Similar results were observed with modified definitions (table 1). At wk 68, significantly greater proportions of ADA vs PBO pts achieved ASDAS endpoints (all $p<0.001$ ), with similar results for protocol-defined and rederived ASDAS calculations, respectively: ID (57.2\% vs $33.3 \%$ and $52.0 \%$ vs $29.4 \%$ ), major improvement $(58.6 \%$ vs $32.0 \%$ and $50.0 \%$ vs $30.7 \%)$, and clinically important improvement $(67.1 \%$ vs $45.1 \%$ and $67.1 \%$ vs $44.4 \%)$
Abstract OP0248 - Table 1 Percentage of patients not experiencing disease flare at week 68 using protocol-defined or rederived ASDAS and/or modified flare definitions

\begin{tabular}{|c|c|c|c|c|}
\hline Variable, $\mathbf{n}(\%)$ & $\begin{array}{c}\text { Adalimumab } \\
(40 \mathrm{mg} \mathrm{EOW}) \\
\mathrm{n}=152^{\star}\end{array}$ & $\begin{array}{l}\text { Placebo } \\
n=153^{\star}\end{array}$ & Difference, \% & $P$ value \\
\hline $\begin{array}{l}\text { Protocol-defined } \\
\text { ASDAS and flare }\end{array}$ & $106(69.7)$ & $72(47.1)$ & 22.7 & $<0.001$ \\
\hline $\begin{array}{l}\text { Rederived ASDAS, } \\
\text { protocol-defined flare }\end{array}$ & $100(65.8)$ & $69(45.1)$ & 20.7 & $<0.001$ \\
\hline $\begin{array}{l}\text { Protocol-defined } \\
\text { ASDAS, modified flare } \\
\text { definition }\end{array}$ & $97(63.8)$ & $56(36.6)$ & 27.2 & $<0.001$ \\
\hline $\begin{array}{l}\text { Rederived ASDAS and } \\
\text { modified flare definition }\end{array}$ & $99(65.1)$ & $65(42.5)$ & 22.6 & $<0.001$ \\
\hline
\end{tabular}

Conclusions: At both open-label and double-blind baseline, mean ASDAS was similar, regardless of the hsCRP value cut-off used. Fewer pts in both treatment groups were categorised as not experiencing a flare when limiting the lowest possible hsCRP value to $2 \mathrm{mg} / \mathrm{L}$ in the ASDAS calculation and/or using a modified flare definition. However, treatment differences remained similar compared with the protocol-defined methodology. Results suggest infrequent clinically relevant differences in ASDAS values with use of either definition for minimum hsCRP and that the use of ASDAS $>2.1$ or ASDAS increase $\geq 0.9$ as the definition of flare is reasonable.

Acknowledgements: AbbVie funded the study and approved the abstract for submission. Medical writing support was provided by Maria Hovenden, $\mathrm{PhD}$, and Janet E. Matsuura, PhD, of Complete Publication Solutions, LLC (North Wales, PA) and was funded by AbbVie.

Disclosure of Interest: R. Landewé Grant/research support from: Abbott, Amgen, Centocor, Novartis, Pfizer, Roche, Schering-Plough, UCB, and Wyeth Consultant for: consulting or advisory board fees from Abbott/AbbVie, Ablynx, Amgen, Astra-Zeneca, Bristol Myers Squibb, Celgene, Janssen (formerly Centocor), Galapagos, GlaxoSmithKline, Novartis, Novo-Nordisk, Merck, Pfizer, Roche, Schering-Plough, TiGenix, UCB, and Wyeth, Speakers bureau: Abbott/AbbVie Amgen, Bristol Myers Squibb, Janssen (formerly Centocor), Merck, Pfizer, Roche, Schering-Plough, UCB, and Wyeth., J. Sieper Grant/research support from: from AbbVie, Janssen, Lilly, Merck, Novartis, Pfizer, Roche, and UCB., Consultant for: from AbbVie, Janssen, Lilly, Merck, Novartis, Pfizer, Roche, and UCB., Speakers bureau: from AbbVie, Janssen, Lilly, Merck, Novartis, Pfizer, Roche, and UCB., U Kiltz Grant/research support from: from AbbVie, Chugai, Grünenthal, MSD, Novartis, Pfizer, Roche and UCB., Consultant for: from AbbVie, Chugai, Grünenthal, MSD, Novartis, Pfizer, Roche and UCB., X. Wang Shareholder of: AbbVie, Employee of: AbbVie, M. Li Shareholder of: AbbVie, Employee of: AbbVie, J. Anderson Shareholder of: AbbVie, Employee of: AbbVie DOI: 10.1136/annrheumdis-2018-eular.2636

\section{OP0249 THE CONTRIBUTION OF STRUCTURAL MRI LESIONS TO DETECTION OF SACROILIITIS IN PATIENTS IN THE ASSESSMENTS IN SPONDYLOARTHRITIS INTERNATIONAL SOCIETY (ASAS) CLASSIFICATION COHORT}

W.P. Maksymowych ${ }^{1}$, M. Østergaard ${ }^{2}$, R.G. Lambert ${ }^{3}$, U. Weber ${ }^{4}$, S.J. Pedersen ${ }^{5}$, J. Sieper ${ }^{6}$, D. Poddubnyy ${ }^{6}$, S. Wichuk ${ }^{1}$, P. Machado ${ }^{7}$, X. Baraliakos ${ }^{8} .{ }^{1}$ Medicine, University of Alberta, Edmonton, Canada; ${ }^{2}$ Rheumatology, Copenhagen Center for Arthritis Research, Copenhagen, Denmark; ${ }^{3}$ Radiology, University of Alberta, Edmonton, Canada; ${ }^{4}$ Rheumatology, King Christian 10th Hospital for Rheumatic Diseases, Graasten; ${ }^{5}$ Rheumatology, Gentofte Hospital, Copenhagen, Denmark; ${ }^{6}$ Rheumatology, Charité Universitätsmedizin Berlin, Berlin, Germany; ${ }^{7}$ Rheumatology, University College London, London, UK; ${ }^{8}$ Rheumatology, Rheumazentrum Ruhrgebiet, Herne, Germany

Background: Active lesions typical of axial spondyloarthritis (axSpA) in the sac roiliac joint (SIJ) were reported by local site readers in about $40 \%$ of patients in the ASAS classification cohort (ASAS-CC) when this study was conducted over 10 years $\mathrm{ago}^{1}$. There has been no data reported on the occurrence of structural lesions in this cohort. Since this study was conducted, there has been considerable progress in our understanding of SIJ lesions observed on MRI, which raises the possibility that MRI scans of patients in the ASAS-CC could now be interpreted substantially differently.

Objectives: To determine the added contribution of structural lesions in the SIJ to the evaluation of sacroiliitis in an inception cohort of patients with axSpA.

Methods: Recently updated MRI lesion definitions for axSpA (ASAS MRI def ${ }^{n}$ ) were recorded in an eCRF that comprises global assessment (lesion present absent) and detailed scoring (SPARCC SIJ inflammation, SPARCC SIJ structural). MRI scans were available in a variety of formats (DICOM $(n=175)$, JPEG $(n=71)$, DICOM film( $n=32)$ ) and sequences, axial and semicoronal orientations, from 278 of the 495 cases who had MRI performed in the ASAS-CC. Image quality 